УДК 343.13, 343.14

DOI https://doi.org/10.17308/vsu.proc.law.2021.1/3284

\title{
СПОСОБЫ ОБЕСПЕЧЕНИЯ СОСТЯЗАТЕЛЬНОГО УГОЛОВНОГО ПРОЦЕССА НА ДОСУДЕБНОЙ СТАДИИ
}

\author{
В. М. Зенцова \\ Национальный исследовательский университет \\ "Высшая школа эконолики" (2. Москва) \\ Поступила в редакцию 9 марта 2020 г.
}

\begin{abstract}
Аннотация: на досудебной стадии уголовного процесса права стороны зашиты на справедливый, состязательный уголовный процесс реализуются в наиленьшей степени. Правовое неравенство заключается, прежде всего, в тол, что адвокат лишен процессуальной возложности салостоятельно собирать доказательства по уголовнолу делу. В статье рассматриваются пути разрешения указанной проблель благодаря введению института следственных судей и право адвоката для иелей защиты вести адвокатское расследование.
\end{abstract}

Ключевые слова: уголовный процесс, доказательства зашиты, приниип состязательности, благоприятствование защите, адвокат, следственныцй судья.

Abstract: at the pre-trial stage of criminal proceedings, the rights of the defence to a fair, adversarial criminal trial are implemented to the least extent. Legal inequality is primarily due to the fact that an advocate is deprived of the procedural possibility to independently collect evidence in a criminal case. The current article deals with the ways of resolving this problematic issue through the introduction of the institution of investigative judges and the right of a counsel (for the defense) to submit evidence (in criminal proceedings).

Key words: criminal process, defense evidence, adversarial principle, favor defensionis, advocate, investigative judges.

Справедливое правосудие в процессуальном смысле - это состязательный процесс, в котором для стороны обвинения и стороны защиты обеспечивается равенство процессуального оружия перед независимым судом. До стадии постановления приговора судом состязательность и справедливость являются взаимоопределяющими понятиями. Иными словами, при гарантированной состязательности процедур по уголовным делам они принципиально признаются справедливыми. Состязательностью, построенной на разделении процессуальных фрунций суда, обвинения и защиты обусловливаются и опосредуются все составляющие процессуальной справедливости в уголовном судопроизводстве.

Несмотря на то что принцип состязательности и равноправия сторон закрепляется в ч. 3 ст. 123 Конституции РФ, а также в ч. 1 ст. 15 Уголовно-процессуального кодекса РФ как распространяющийся на всё судопроизводство в целом, его действие обеспечено не на всех стадиях уголовного процесса должным образом.

(C) Зенцова В. М., 2021 
Коренная причина отсутствия подлинной состязательности в уголовном процессе состоит в том, что сторона обвинения и сторона защиты находятся исходно в неравном положении, поскольку сторона обвинения поддерживается представителями публичной власти, в то время как сторона защиты - адвокатом, представителем независимой адвокатской корпорации.

В целях нивелирования объективной разницы в возможностях сторон и достижения должных состязательных начал в процедурах привлечения к уголовной ответственности наукой и законодательством об уголовном судопроизводстве разработана и закреплена система мер, аккумулирующая ряд особых процессуальных гарантий. Они направлены на выравнивание положения сторон не только через предоставление им номинально равных процессуальных прав, но и путем признания определенных преимуществ для защиты от обвинения, что и составляет содержание принципа благоприятствования защите (favor defensionis).

Под благоприятствованием защите, которое не зависит от дискреции суда, а обеспечивается законол, понимаются уголовно-процессуальные нормы и институты, «наделяющие сторону защиты дополнительными правами или освобождающие ее от обязанностей либо иным образом ставящие ее в юридически более выгодное положение по сравнению со стороной обвинения, специально сконструированные с непосредственной целью компенсации процессуального неравенства сторон при решении вопроса о виновности подсудимого»1․

Несмотря на то что терминологически принцип благоприятствования защите в законе так и не назван, он во всех образующих его элементах имеет нормативное закрепление в уголовно-процессуальном праве. $\mathrm{K}$ числу необходимых его составляющих относятся:

1) презумпция невиновностиㄹ;

2) запрет использования стороной обвинения недопустимых доказательств, т. е. доказательств, полученных с нарушением закона ${ }^{3}$;

3) асимметрия правил о допустимости доказательств, предполагающая возможность для стороны защиты использовать недопустимые доказательства. Данное положение обусловлено тем, что основной массив доказательств по уголовному делу собирает представитель стороны обвинения, соответственно, его процессуальная ошибка, допущенная при сборе доказательств, подтверждающих невиновность лица, может служить основанием для признания таких доказательств недопустимыми. Защитник, в свою очередь, имеет право ссылаться на доказательства невиновности, полученные с нарушением закона, если данные доказательства могут благоприятно сказаться на участи подзащитного;

${ }^{1}$ Мuхеенкова M. А. Благоприятствование защите (favor defensionis) и его проявление в современном уголовном процессе : дис. ... канд. юрид. наук. М., 2012. C. 75

2 Часть 1 ст. 14 УПК РФ. Здесь и далее все ссылки на нормативно-правовые акты и судебную практику приводятся по справ.-правовой системе «КонсультантПлюс». URL: http://www.consultant.ru/ (дата обращения: 29.02.2020).

${ }^{3}$ Статья 75 УПК РФ. 
4) запрет использования преюдиции в качестве подтверждения виновности лиц, не участвовавших ранее при рассмотрении дела, по которому был вынесен преюдициальный судебный акт4. Это обусловлено, в частности, тем, что большинство уголовных дел рассматривается в особом порядке, без исследования доказательств. В таких процессах виновность не устанавливается - это своего рода сделка между стороной защиты и обвинения; по этой причине факты, установленные в приговоре в отношении другого лица, не могут иметь преюдициального значения для иных лиц, привлекаемых к уголовной ответственности;

5) толкование сомнений в виновности обвиняемого (подсудимого) в его пользу ${ }^{5}$;

6) порядок исследования доказательств, предоставляющий стороне защиты право представлять доказательства последней ${ }^{6}$, что позволяет ей реагировать на ранее представленные доказательства обвинения;

7) порядок прений сторон ${ }^{7}$;

8) право на последнее слово подсудимого 8 ;

9) порядок подсчета голосов присяжных заседателей9 ${ }^{9}$ предполагающий принятие решения в пользу подсудимого, в случае если голоса разделены поровну;

10) запрет поворота к худшему при пересмотре приговора по инициативе осужденного ${ }^{10}$;

11) сроки пересмотра приговора по инициативе государственного обвинителя, потерпевшего (частного обвинителя), гражданского истца или их представителей ${ }^{11}$.

Представляется интересным вопрос о соотношении принципа состязательности и равенства сторон с благоприятствованием защите. Сторонники обвинительной модели уголовного процесса могут прибегать к - доводу о том, что названные принципы являются взаимоисключающими.

Цель, преследуемая принципом состязательности, заключается в предоставлении сторонам уголовного процесса равных прав, в том числе процессуальных. В свете этого принцип благоприятствования защите необходим не для создания особых привилегий, а для устранения существенного неравенства между стороной обвинения и стороной защиты.

${ }^{4}$ Статья 90 УПК РФ.

${ }^{5}$ См.: Часть 3 ст. 14 УПК РФ ; По делу о проверке конституционности положений п. 1,3 ч. 1 ст. 232 , ч. 4 ст. 248 и ч. 1 ст. 258 УПК РСФСР в связи с запросами Иркутского районного суда Иркутской области и Советского районного суда города Нижний Новгород : постановление Конституционного Суда РФ от 20 апреля 1999 г. № 7-П (п. 15).

6 Часть 2 ст. 274 УПК РФ.

${ }^{7}$ Статья 292 УПК РФ.

${ }^{8}$ Статья 293 УПК РФ.

${ }^{9}$ Статья 343 УПК РФ.

${ }^{10}$ Статья 389.24 УПК РФ.

11 Часть 4 ст. 389.8, ст. 401.6 УПК РФ. 
Принцип состязательности провозглашает право на состязательный уголовный процесс, но сам по себе еще не обеспечивает его достижения. Ввиду того, что стороны изначально неравны в своих силах, признание за ними равных прав и обязанностей не устраняет неравенство, обусловленное разным субъектным составом сторон (с одной стороны, представители публичной власти, с другой - обвиняемый и его адвокат, член профессиональной корпорации, являющейся институтом гражданского общества $\left.{ }^{12}\right)$.

Представляется, что признание необходимым правовых мер благоприятствования защите является результатом әволюционирования принципа состязательности. В то время как принцип состязательности отождествляют с равенством процессуального оружия, принцип благоприятствования защите подтверждает идею о том, что самого по себе равенства процессуального оружия недостаточно, чтобы уголовный процесс был справедливым.

Для понимания необходимости принципа благоприятствования защите следует обратиться к классическим моделям уголовного процесса и сравнению состязательных и инквизиционных процедур.

В странах романо-германского права в XVIII в. использовалась классическая модель инквизиционного уголовного процесса, для которой определяющим было доминирующее положение стороны обвинения по отношению к стороне защиты, для нее характерны следующие черты:

1) отправление правосудия профессиональным судьей - представителем судебной власти как разновидности власти публичной, использующей властные полномочия для преследования гражданина;

2) значительная роль досудебной стадии уголовного процесса и получение в этой стадии доказательств без судебного контроля;

3) система формальных доказательств;

4) применение пыток в целях получения признания (на ранних стадиях производства).

Перечисленные черты инквизиционного процесса обеспечивали стороне обвинения неоспоримые преимущества и исключали существование равенства и состязательности в уголовном процессе. Более того, вес досудебного производства в сочетании с системой формальных доказательств и пытками являлся свидетельством абсолютного господства стороны обвинения над стороной защиты.

Состязательный уголовный процесс - полная противоположность инквизиционного процесса. Поддержание в нем дополнительными правилами определенных преимущественных прав для стороны защиты (т. е. внедрение элементов принципа благоприятствования защите) является естественным процессом для современного и гуманного общества.

Так же как пытки являлись олицетворением инквизиционного процесса, элементы принципа благоприятствования защите, такие как

12 Об адвокатской деятельности и адвокатуре в Российской Федерации : феедер. закон от 31 мая 2002 г. № 63-ФЗ (ч. 1 ст. 3). 


\section{Вестник ВГУ. Серия: Право}

презумпция невинности, право не свидетельствовать против себя, право на последнее слово и т. д., являются воплощением состязательного уголовного процесса, служат состязательности.

Соотношение принципов состязательности сторон и благоприятствования защите позволяет утверждать, что принцип благоприятствования защите является эволюционной надстройкой к содержанию принципа состязательности сторон, выступает как элемент его новой, более прогрессивной и гуманной формы. И именно в таком их понимании эти принципы закреплены в нормах Конституции и Уголовно-процессуального кодекса РФ как действующие на всех стадиях уголовного судопроизводства.

Однако на досудебной стадии уголовного процесса это оказывается не реализуемым, поскольку состязательность для сторон обвинения и защиты обусловлена появлением в процессе независимого арбитра - судьи.

Разумеется, фригура судьи возникает на досудебной стадии, но лишь в отдельные моменты процесса, например при избрании меры пресечения или для дачи разрешения на проведение следственных действий, связанных с ограничением конституционных прав. В остальных случаях уголовный процесс на досудебной стадии обнаруживает классические признаки инквизиционного (розыскного) процесса.

Состязательность на досудебной стадии уголовного процесса оказывается невозможной по причинам институционально-организационного характера: здесь нет независимого представителя публичной власти, обеспечивающего процессуальное равноправие стороны обвинения и стороны защиты.

Адвокат-защитник правомочен обратиться в суд в порядке ст. 125 УПК РФ с жалобой на действия лица, проводящего расследование по уголовному делу. Однако, во-первых, это будет не оперативно. Во-вторых, не эфрективно, поскольку суд вправе обязать лицо, осуществляющее расследование по уголовному делу, устранить допущенные процессуальные нарушения, но не вправе давать конкретные указания о производстве предварительного расследования.

Реальная состязательность на досудебной стадии уголовного процесса требует его кардинального институционального перестроения.

Существующее конституционное регулирование не только позволяет, но и обязывает законодателя наделить более слабую сторону защиты дополнительными процессуальными гарантиями на досудебной стадии. Недостатки этой стадии могут быть нейтрализованы с помощью развития разных процессуальных институтов, среди которых с большей или меньшей активностью обсуждаются:

1) снижение значимости предварительного расследования, развитие приоритета доказывания перед судом;

2) институт следственного судьи;

3) введение самостоятельного адвокатского расследования.

Последовательное рассмотрение заявленных мер позволяет увидеть также и их взаимосвязь. 


\section{Снижение значимости предварительного расследования, развитие приоритета доказывания перед судом}

Существо проблемы состоит в том, что стадия предварительного расследования негласно «узурпировала» то, что ей не принадлежит, а именно разрешение дела по существу и установление виновных лиц. На лиц, осуществляющих предварительное расследование, возложена невыполнимая законными методами задача - направить дело с обвинительным заключением (обвинительным актом) прокурору, с доказательственной базой, исключающей сомнения в виновности привлекаемого к ответственности. В противном случае прокурор просто не утвердит обвинительное заключение (обвинительный акт).

По этой причине следователи и дознаватели всячески противодействуют стороне защиты в создании контробвинительных и тем более оправдательных версий совершенного преступления.

Излишний канцеляризм вытесняет справедливость из современного уголовного процесса. В ходе предварительного расследования стороной обвинения используется метод “умножения» доказательств виновности обвиняемого. Фактически из одного доказательства искусственным образом создается несколько доказательств виновности, в то время как адвокат не наделен правом самостоятельно собирать доказательства по уголовному делу.

Например, в материалах уголовного дела имеется цифровой носитель информации, содержащий видеозапись события преступления. Ответственный следователь непременно составит протокол осмотра видеозаписи, в котором даст собственную трактовку запечатленным на видеозаписи событиям. В последующем в суд в числе прочих материалов уголовного дела поступят два доказательства виновности.

Отдельного внимания заслуживают свидетельские показания как вид доказательств. Допрос лиц, обладающих информацией об обстоятельствах совершенного преступления на досудебной стадии осуществляет следователь, соответственно, он обладает возможностью направлять ход допроса в соответствии с избранной им версией преступления, путем постановки вопросов (используя в том числе тактические методы криминалистики).

Таким образом, фрормируется доказательство - протокол допроса свидетеля, который содержит искаженную информацию об обстоятельствах преступления, поскольку был составлен заинтересованным лицом, осуществляющим предварительное расследование.

В правоприменительной практике повсеместно распространены расхождения между показаниями свидетеля, данными на досудебной стадии и в зале судебного заседания. Причина указанных расхождений в том, что в первом случае допрос осуществляется стороной, заинтересованной в раскрытии преступления и изобличении виновного лица, а во втором случае - всеми участниками уголовного процесса. 
Очевидно, что более объективными являются показания, данные свидетелем в ходе допроса в зале судебного заседания. Однако государственный обвинитель в каждом случае заявляет ходатайство об оглашении показаний, данных свидетелем на стадии предварительного расследования ввиду наличия существенных противоречий. После оглашения свидетелю задается провокационный вопрос о том, когда свидетель лучше помнил обстоятельства уголовного дела. Разумеется, свидетель дает ответ, что на досудебной стадии он помнил обстоятельства лучше, потому что давал их раньше.

Истинная же причина наличия противоречий в показаниях свидетелей состоит в том, что допрос на досудебной стадии проводился представителем стороны обвинения и, безусловно, был лишен объективности.

Отсутствие равенства сторон в процессе собирания доказательств по уголовному делу на досудебной стадии приводит к тому, что порочные и искаженные субъективизмом доказательства направляются в судебную стадию, исследуются судом и учитываются при вынесении приговора. Исследование же в судебной стадии производства протоколов допросов, проведенных следователем, при наличии явки в зал суда самого свидетеля представляется одним из проявлений обвинительного уклона, что исключает справедливость уголовного процесса в целом.

Снижение значимости предварительного расследования и развитие приоритета доказывания перед судом возможно посредством установления запрета на исследование в зале суда протоколов следственных действий, при личной явке свидетелей в суд или при наличии возможности у суда самостоятельно исследовать предметы и документы. Этим может косвенно обосновываться также сокращение процессуальных сроков предварительного расследования. Задача следственных органов должна - состоять не в том, чтобы «установить» виновность лица путем составле이 ния нескольких десятков томов уголовного дела, а в том, чтобы представить перед судом убедительную версию совершенного преступления.

Представляется также целесообразным отказаться от практики возвращения прокурору уголовного дела, в расследовании которого суд обнаружил недостатки и противоречия. Судья обладает достаточными полномочиями и квалификацией для устранения противоречий в ходе судебного следствия. Полагаем, что это более эффрективно и справедливо. Тем более, что у судьи есть не только право, но и объективные основания реализовать конституционный принцип истолкования всех сомнений в пользу подозреваемого (обвиняемого), что является также истинным воплощением принципа «favor defensionis».

Уголовное дело должно разрешаться перед профессиональным судьей, и итог разбирательства не может предопределяться доказательственной базой, собранной без участия в ее формировании стороны защиты, что с точки зрения принципа состязательности является неправомерным.

Разрешение проблемы отсутствия у стороны защиты достаточных прав на досудебной стадии уголовного процесса имеет положительные примеры в отечественной истории. Изучение процессов по конкретным 
делам после Судебной реформы 1864 г. демонстрирует, что справедливое правосудие не измеряется десятками томов уголовных дел, на подготовку которых на протяжении долгих месяцев и даже лет направлены усилия современных следователей и дознавателей. В пореформенное время в Российской империи была реализована модель уголовного процесса, в которой досудебная стадия проводилась в более сжатые сроки

В Российской империи, с момента принятия Учреждения судебных установлений, Устава уголовного судопроизводства, а также Устава о наказаниях, налагаемых мировыми судьями, действовал состязательный уголовный процесс, в котором стороны были действительно равны в своих процессуальных правах ${ }^{13}$.

На досудебной стадии следствие осуществлялось полицией и состоящими при окружных судах следственными судьями, которые в соответствии с п. 147 Учреждения судебных установлений не могли участвовать в рассмотрении тех уголовных дел, по которым они производили следствие $^{14}$. Согласно п. 265 Устава уголовного судопроизводства на них при производстве следствия возлагалась обязанность «с полным беспристрастием приводить в известность как обстоятельства, уличающие обвиняемого, так и обстоятельства, его оправдывающие» ${ }^{15}$. Согласно п. 105 некоторые виды следственных действий - осмотры, освидетельствования и обыски - «могли проводиться мировым судьей или, по его поручению, чинами местной полиции» ${ }^{16}$.

Приведенные нормы подтверждают преобладание значимости судебной стадии над досудебной. Сами представители судейского сообщества были вовлечены не только в процесс оценки доказательств, но и в процесс сбора доказательств, если возникала такая необходимость. Уголовное дело разрешалось непосредственно перед судьей и судом присяжных, правомочными принимать по нему решения о виновности и возможном наказании.

Важно отметить, что судебный следователь эпохи Судебной реформы 1864 г. не являлся аналогом современного следственного судьи.

\section{Институт следственного судьи}

Современная идея введения в уголовный процесс института следственных судей по своей сути отличается от фигуры судебного следоваएo 3 теля. Эти участники процесса осуществляют совершенно разные процессуальные роли. Судебный следователь обладал полномочием по производству расследования, в то время как следственный судья имеет право вмешаться в процесс расследования уголовного дела «ad hoc», т. е. при наличии спора между стороной обвинения и защиты.

13 Такие процедуры существовали вплоть до принятия Советом народных комиссаров Декрета о суде № 1 от 24 ноября 1917 г., упразднившего прежнюю судебную систему.

${ }^{14}$ Пункт 147 Учреждения судебных установлений 1864 г.

15 Пункт 265 Устава уголовного судопроизводства 1864 г.

${ }^{16}$ Пункт 105 Устава уголовного судопроизводства 1864 г. 
Введение института следственных судей в недавнем прошлом было инициировано заслуженным юристом Российской Федерации, доктором юридических наук, профессором А. В. Смирновым. В 2015 г. им была разработана концепция «Возрождение института следственных судей в российском уголовном процессе», предложен законопроект, который, к сожалению, не приобрел статус нормативного акта ${ }^{17}$. Основные черты этой концепции докладывались также на заседании Совета по правам человека при Президенте РФ в марте 2015 г. заслуженным юристом Российской Федерации, доктором юридических наук Т. Г. Морщаковой ${ }^{18}$.

Дискуссии о введении института следственных судей активно ведутся. В декабре 2019 г. на заседании Совета по правам человека при Президенте РФ вице-президентом ФПА РФ Г. М. Резником вновь предложено «вернуться к осмыслению фигуры следственного судьи» ${ }^{19}$, и Президент признал необходимость рассмотрения этой идеи и введения института следственных судей ${ }^{20}$, что свидетельствует о ее актуальности.

В рамках настоящей статьи институт следственных судей рассматривается как механизм, способный устранить отсутствие равенства сторон на досудебной стадии уголовного процесса, приводящего к невозможности обеспечения его состязательности.

Полномочия следственного судьи предлагается разделить на четыре основные категории: 1) разрешение органам расследования проведения следственных действий, ограничивающих конституционные права граждан; 2) рассмотрение ходатайств органов предварительного расследования об избрании и продлении отдельных видов мер пресечения; 3) рассмотрение жалоб, поданных стороной защиты в порядке ст. 125 УПК РФ, в процессе обжалования действий лиц, осуществляющих предварительное расследование; 4) признание сведений, собранных стороной защиты, доказательствами по уголовному делу после проверки в порядке ст. 87 УПК РФ.

В существующем уголовно-процессуальном регламенте фрункции следственного судьи частично выполняет судья, осуществляющий в соответствии с положениями УПК РФ судебный контроль на досудебных стадиях, т. е. разрешающий органам расследования проведение следственных действий, ограничивающих конституционные права граждан: обысков, прослушивание переговоров и т. д.; рассматривающий ходатайства органов предварительного расследования о применении ареста как меры пресечения, а также разрешающего жалобы в порядке ст. 125 УПК

17 См.: Пояснительная записка к законопроекту о возрождении института следственных судей, подготовленная советником Конституционного Суда Российской Федерации, заслуженным юристом Российской Федерации, доктором юридических наук, профессором А. В. Смирновым.

18 URL: https://advstreet.ru/article/sledstvennye-sudi-novaya-nadezhda (дата обращения: 29.02.2020).

${ }^{19}$ URL: https://advstreet.ru/article/sledstvennye-sudi-novaya-nadezhda (дата обращения: 29.02.2020).

20 Там же. 
РФ ${ }^{21}$. Указанные процессуальные полномочия не являются достаточными для обеспечения состязательного уголовного процесса, поскольку не обеспечивают стороне защиты прямой доступ к процедуре создания доказательств по уголовному делу.

Три из четырех полномочий следственного судьи (см. п. 1-3) в настоящее время возложены на обычного судью, рассматривающего уголовные дела по существу. Нельзя не видеть существенные риски в подобном смешении полномочий, поскольку судья, избравший меру пресечения лицу, в отношении которого ведется производство по уголовному делу, в последующем может получить указанное дело к производству, т. е. будет рассматривать уголовное дело с предубеждением о виновности.

В соответствии с ч. 1 ст. 47 Конституции РФ никто не может быть лишен права на рассмотрение дела в том суде и тем судьей, к подсудности которых оно отнесено законом. Уголовно-процессуальное законодательство на сегодняшний день никак не ограничивает возможность повторного назначения судьи, ранее осуществлявшего судебный контроль за следствием, рассматривать уголовное дело по существу.

В случае разделения судейских полномочий между судьями, рассматривающими дело по существу, и следственными судьями указанная проблема прекратила бы свое существование.

Научное сообщество по-прежнему полярно разделено относительно идей введения института следственных судей. Так, доктор юридических наук, профессор Л. В. Головко в своем недавнем интервью высказал позицию: «...такие "профилированные» судьи тут же срастутся со следствием» ${ }^{22}$. Данная мотивировка представляется ценным замечанием об ожидаемых рисках. Действительно, правоприменительной практике свойственно искажать благие идеи законодателя, однако это не значит, что необходимо отказаться от реформирования досудебной стадии уголовного процесса.

Как справедливо было отмечено А. В. Смирновым, интересы обеспечения равенства реализуются за счет существенного усиления под контролем следственного судьи возможностей стороны защиты по собиранию доказательств ${ }^{23}$.

Необходимость введения института следственных судей также поддерживается Т. Г. Морщаковой, которой назван один из главных дефектов нынешнего УПК РФ - господство на так называемых досудебных стадиях процесса стороны обвинения и фрактическое процессуальное неравноправие с ним стороны защиты, в результате чего судебные доказательства фрормируются, по сути, одним лишь публичным обвинителем

${ }^{21}$ См.: Пиюк А. В. «Следственный судья» или «судебный следователь» : какая редорма нам нужна?» // Уголовная юстиция. 2014. № 2. С. 24-28.

${ }^{22}$ URL: https://advstreet.ru/article/sledstvennye-sudi-novaya-nadezhda/ (дата обращения: 11.02.2020).

23 Российское агентство правовой и судебной информации. URL: http:// rapsinews.ru/judicial_analyst/20141202/272697983.html (дата обращения: 10.09.2020). 
(следователем, дознавателем), тогда как другая сторона - защита - такой возможностью не обладает ${ }^{24}$. Однако до тех пор, пока адвокат зависим от следователя и не способен без его участия собирать доказательства, стороны не равны.

\section{Введение самостоятельного адвокатского расследования}

Адвокатское расследование - процессуальное достижение, которое возможно исключительно благодаря введению института следственных судей. Главные черты адвокатского расследования должны состоять в следующем: 1) независимость от органов, осуществляющих предварительное расследование; 2) подконтрольность следственному судье; 3) фрормирование доказательств невиновности (смягчающих вину), охраняемых адвокатской тайной (по аналогии с режимом тайны следствия); 4) необязательный характер адвокатского расследования. Отсутствие доказательств невиновности, собранных адвокатом, не должно трактоваться против интересов лица, в отношении которого ведется производство по уголовному делу, поскольку иное искажало бы презумпцию невиновности.

По мнению А. В. Смирнова, предварительная подготовка доказательств стороной обвинения в условиях тайны следствия, при отсутствии симметричной возможности у стороны защиты гарантирует представителям государства победу в судебном поединке ${ }^{25}$.

В уголовном процессе Российской Федерации две его стадии характеризуются совершенно различающимся уровнем соблюдения прав лица, в отношении которого ведется производство по уголовному делу. На судебной стадии обеспечиваются состязательность и равенство сторон. Однако досудебная стадия является антиподом равенства сторон. Состязательности на досудебной стадии фактически нет, поскольку производство по

- уголовному делу осуществляет исключительно должностное лицо, неза인 интересованное в поддержании стороны защиты.

В дальнейшем доказательства, созданные в условиях отсутствия состязательности и равенства участников уголовного процесса, направляются на судебную стадию и негативно влияют на процесс рассмотрения уголовного дела судом. За исключением случаев признания доказа-

286 тельств, собранных на досудебной стадии недопустимыми, они подлежат учету при постановлении приговора. Таким образом, формируется обвинительный уклон уголовного судопроизводства, поскольку в его основе преимущественно лежат доказательства, созданные лицом, осуществлявшим предварительное расследование.

${ }^{24}$ Сайт Совета по правам человека при Президенте РФ. О компетенции и порядке формирования института следственных судей в Российской Федерации. URL: $\quad$ http://president-sovet.ru/files/bf/f9/bff99bb741943f8aa3e9c0b85cdeb243.pdf (дата обращения: 11.02.2020).

25 Российское агентство правовой и судебной информации. URL: http:// rapsinews.ru/judicial_analyst/20141202/272697983.html (дата обращения: 10.09.2020). 
Лицо, осуществляющее предварительное расследование и защитник на досудебной стадии являются процессуальными противниками. Цели их деятельности принципиально отличаются, по этой причине их совместная деятельность в вопросах сбора и оценки доказательств по уголовному делу неэффективна. Представляется логичным разделение расследования, проводимого должностным лицом, и адвокатского расследования. Защитник должен быть независим от следователя и обладать процессуальной фрункцией проведения собственного расследования.

Наиболее прогрессивной представляется такая модель уголовного процесса, в которой доказательства, собранные в рамках адвокатского расследования, не будут соединяться с материалами уголовного дела, подготовленными следователем, до момента окончания предварительного следствия и ознакомления обвиняемого с материалами уголовного дела в порядке ст. 217 УПК РФ.

Сведения, признанные следственным судьей по ходатайству адвоката доказательствами по уголовному делу, должны охраняться режимом адвокатской тайны, поскольку иное противоречит принципу равенства участников уголовного судопроизводства. Сторона защиты не имеет доступа ко всем доказательствам, собранным следователем до момента окончания предварительного следствия. Соответственно, следователь также должен быть лишен права доступа к доказательствам, собранным в рамках адвокатского расследования.

Соединение доказательств, собранных в рамках адвокатского расследования с материалами уголовного дела, должно осуществляться следователем в безакцептном порядке, поскольку проверка указанных доказательств в соответствии со ст. 87 УПК РФ была проведена независимым следственным судьей. Предполагается, что защитник будет представлять следователю по окончании производства по уголовному делу доказательства, собранные в рамках адвокатского расследования, с резолющией следственного судьи, проводящего проверку указанных доказательств. Следователь будет передавать вместе с обвинительным заключением и материалами уголовного дела материалы адвокатского расследования, не проводя их дополнительной проверки.

Механизм соединения доказательств защиты и обвинения частично закреплен ч. 4 ст. 217 УПК РФ, которая предусматривает выяснение имеएo 3 ющихся у стороны защиты ходатайств, предложений о вызове в суд свидетелей, экспертов, специалистов и должна быть дополнена указанием на приобщение доказательств, собранных в рамках адвокатского расследования.

В настоящее время сторона защиты не имеет права самостоятельно собирать доказательства по уголовному делу. На досудебной стадии все доказательства по уголовному делу собираются стороной обвинения или приобщаются с согласия стороны обвинения. Поскольку должностное лицо, в производстве которого находится уголовное дело, не заинтересовано приобщать в качестве доказательств сведения, не согласующиеся с 
позицией обвинения, сторона защиты лишена возможности полноценно участвовать в процедуре доказывания.

Для достижения состязательного уголовного процесса на досудебной стадии необходимо реформировать существующую модель уголовного процесса путем внедрения элементов, описанных в настоящей статье: института следственных судей и независимого адвокатского расследования, в рамках которого будут формироваться доказательства по уголовному делу.

Национальный исследовательский университет "Высшая школа экономики» (г. Москва)

Зенцова В. М., аспирант кафбедры судебной власти

E-mail:v.zentsova@mail.ru
National Research University "The Higher School of Economics"

Zentsova V. M., Post-graduate Student of the Judicial Authority Department E-mail:v.zentsova@mail.ru 